\title{
Rammya Mathew: We need to rise above racist abuse and challenge attitudes
}

\author{
Rammya Mathew GP \\ London
}

The recent case of Radhakrishna Shanbhag, a senior trauma and orthopaedic surgeon who was asked by a patient if a white doctor could do his operation instead, has hit the headlines. ${ }^{1}$ It shines a light on how prevalent racist attitudes are in today's society. It also raises the question of how the NHS should deal with such requests-which are more common than you might imagine.

The obvious answer is to have a zero tolerance policy, where patients who discriminate against NHS staff for any reason are reprimanded for their behaviour. Many doctors expressed disbelief that the patient in this recent story was offered an alternative date for surgery because of his preference for a white doctor. I empathise with this perspective, as I know how damning it can feel for BAME doctors when the system doesn't support you in standing up to racism.

But what's the appropriate response in these circumstances? What if the patient was refused surgery and came to harm? Andrew Foster, former chief executive of the Wrightington, Wigan, and Leigh NHS Foundation Trust, has spoken about a similar incident where a patient was not excluded, as clinical staff were concerned that the patient wouldn't be able to access

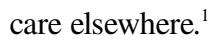

The bottom line is that we're not in the business of offering care only to "good" people. Our duty of care extends to racists, xenophobes, and all manner of people with less than perfect characteristics. Of course, we have to draw the line somewhere, so that our staff feel protected and supported and so that the NHS isn't perceived as an organisation that promotes or accepts racism. But is the right answer to punish patients by refusing them care or by sending them to the back of the queue? I worry that this approach would reinforce any ignorance or fear that might underlie their prejudices and that the same problem would continue to rear its ugly head elsewhere in society. ${ }^{2}$

In the run-up to the US election in 2016, researchers found a radical way of tackling prejudice. They discovered that a 10 minute non-confrontational conversation, which actively encouraged all participants to put themselves in the shoes of "the other person," helped to reduce prejudiced views. ${ }^{3}$ Is it really that simple? It won't always be. But it suggests that we need to rise above people's ignorance and challenge these attitudes with open dialogue, countering them with compassion rather than retribution. The evidence indicates that this is how you change people's mindsets, rather than being confrontational and calling them racist. $^{4}$

It's not the NHS's responsibility to fix racism, but it is our responsibility to care for patients. If we can change the way people think, by demonstrating care and compassion in times of vulnerability, surely this can only be a good thing.

Competing interests: I co-lead Islington GP Federation's Quality Improvement Team.

Provenance and peer review: Commissioned; not externally peer reviewed.

1 Rimmer A. Don't accept racist abuse, Hancock tells NHS staff. BMJ 2019;367:16425 10.1136/bmj.16425 31699785

2 DiAngelo R. White fragility. Int J Crit Pedagog 2011:3:54-70.

3 Broockman D, Kalla J. Durably reducing transphobia: A field experiment on door-to-door canvassing. Science 2016;352:220-4. https://www.gsb.stanford.edu/faculty-research/ publications/durably-reducing-transphobia-field-experiment-door-door-canvassing. 10.1126/science.aad9713 27124458

4 Lopez G. Research says there are ways to reduce racial bias. Calling people racist isn't one of them. Vox 2018 Jul 30. https://www.vox.com/identities/2016/11/15/13595508/ racism-research-study-trump.

Published by the BMJ Publishing Group Limited. For permission to use (where not already granted under a licence) please go to http://group.bmj.com/group/rights-licensing/ permissions 